\title{
Rathke's Cleft Cyst with Short-Term Size Changes in Response to Glucocorticoid Replacement
}

\author{
HIROSHI MARUYAMA, YASUMASA IWASAKI, MAKOTO TSUGITA, NAOKO OGAMI, KOICHI ASABA, \\ TOSHIHIRO TAKAO, HIROMICHI NAKABAYASHI, KEIJI SHIMIZU AND KOZO HASHIMOTO \\ Departments of Endocrinology, Metabolism, and Nephrology, and Neurosurgery, Kochi Medical School, Kochi University, Kohasu, \\ Oko-cho, Nankoku 783-8505, Japan
}

\begin{abstract}
An 81-year-old man was admitted to our hospital because of general fatigue. Hormonal examination showed that he had panhypopituitarism and central diabetes insipidus. MRI imaging revealed the presence of large cystic mass with suprasellar extension in his hypothalamo-pituitary region. Interestingly, the cystic mass shrank following the start of glucocorticoid replacement, and since then relatively high doses of cortisol administration were needed to prevent the re-enlargement of cystic size. Because of the concern over possible side effects of supraphysiological doses of glucocorticoid replacement, surgical treatment was eventually carried out, confirming the pathological feature of Rathke's cleft cyst. The present case suggests that the inflammatory nature of Rathke's cleft cyst may explain the observed short-term size changes in response to glucocorticoid administration.
\end{abstract}

Key words: Rathke's cleft cyst, Pituitary tumor, Hypopituitarism, Glucocorticoid

(Endocrine Journal 55: 425-428, 2008)

RATHKE'S cleft cyst (RCC) is a relatively common disorder of the hypothalamo-pituitary region. From an anatomical standpoint, Teramoto et al. [1] found the presence of RCCs in $3.7 \%$ of autopsy cases. In a clinical setting, Sanno et al. [2] reported the RCCs in $15.9 \%$ of the surgical group and $39.5 \%$ of the non-surgical group of pituitary mass lesions treated as "pituitary incidentaloma". It is also known that RCCs often impair pituitary function, and even cause visual disturbances due to suprasellar extension with compression of the optic chiasm [3].

We recently encountered a case of RCC, which manifested enlargement and shrinkage during a relatively short time period. Interestingly, the cystic size repeatedly decreased when the daily dose of cortisol replacement was increased. Since some RCCs are reported to

Received: September 24, 2007

Accepted: November 1, 2007

Correspondence to: Yasumasa IWASAKI, M.D., Ph.D., Department of Endocrinology, Metabolism, and Nephrology, Kochi Medical School, Kochi University, Kohasu, Oko-cho, Nankoku 783-8505, Japan have an inflammatory nature, we assumed that the antiinflammatory effect of glucocorticoid may partly be responsible for the observed short-term alteration in cystic size.

\section{Case report}

An 81-year-old man was introduced to our outpatient clinic because of general fatigue, headache, and lowgrade fever. He had received a surgical treatment of prostate carcinoma at 59-year-old, without recurrence. He had also suffered from mild cerebellar infarction in his seventies. Four months ago, he began to experience general fatigue, anorexia and low-grade fever. Initially, he was diagnosed as urinary tract infection at a local clinic, but antibiotic administration failed to eliminate his symptoms. Hormonal examination revealed that his serum cortisol level in the morning was relatively low $(2.4 \mu \mathrm{g} / \mathrm{dl})$, and he was referred to our hospital for further examination.

On admission, he was alert and oriented, and no specific physical finding was observed except that he was 
severely dehydrated. His body mass index, body temperature, blood pressure were $22.5 \mathrm{~kg} / \mathrm{m}^{2}, 37.8^{\circ} \mathrm{C}$, and $120 / 60 \mathrm{mmHg}$, respectively. Blood examination showed that he had electrolyte abnormalities ( $\mathrm{Na} 158 \mathrm{mmol} / \mathrm{l}$ and $\mathrm{Cl} 121 \mathrm{mmol} / \mathrm{l})$, leukocytosis $(11100 / \mu \mathrm{l})$, and inflammation (ESR $113 \mathrm{~mm} / \mathrm{hr}$, CRP $10.1 \mathrm{mg} / \mathrm{dl}$ ). No finding of overt infections such as cystitis and pneumonia was obtained.

Endocrinological examination showed that he had hypopituitarism. Plasma levels of ACTH and cortisol were low with impaired diurnal changes (Table 1A), and provocation tests showed that $\mathrm{LH} / \mathrm{FSH}$ and TSH/ PRL responses to GnRH and TRH, respectively, were markedly impaired (Table 1B). Plasma cortisol responses to CRH were also blunted although those of ACTH were preserved, suggesting the presence of mixed hypothalamic and pituitary damages. Hypertonic saline infusion test also showed that he had central diabetes insipidus (DI) (Table 1C). Magnetic resonance imaging (MRI) examination revealed a large cystic mass characteristic of RCC in the sella turcica with suprasellar extension (Fig. 1A). Normal anterior pituitary gland and the high intensity signal corresponding to the posterior pituitary gland were not recognized. Neither enhancement of the mass itself nor ring enhancement was observed with gadolinium (not shown). Taken together, we diagnosed that he had both anterior and posterior pituitary dysfunction due to RCC. Since he continued to have low-grade fever and positive CRP, cortisol replacement of relatively high dose $(30 \mathrm{mg} /$ day $)$ was started, which improved his general condition, with marked shrinkage of RCC (Fig. 1B). His daily urine volume also increased up to 4 1/day due to unmasking of masked DI, and DDAVP administration was started.

During the follow-up in our outpatient clinic, daily dose of cortisol replacement was decreased to $10 \mathrm{mg} /$ day. Two weeks later he started to complain headache, and enlargement of RCC was recognized by MRI examination (Fig. 1C). He also showed low-grade fever, and thus daily cortisol replacement was increased to $20 \mathrm{mg} /$ day, which transiently improved his symptoms and caused the shrinkage of RCC again (Fig. 1D). However, three months later reappearance of the symptoms and re-growth of the cyst occurred (Fig. 1E), which was again subsided by increasing the daily dose of cortisol to $30 \mathrm{mg}$ (Fig. 1F). Because of concern over possible metabolic side effects of high-dose glucocorticoid treatment, the patient eventually had resection of
Table 1A. Endocrinological examination

\begin{tabular}{|c|c|c|c|}
\hline HPA axis & am 8 & pm 4 & pm 11 \\
\hline $\mathrm{ACTH}(\mathrm{pg} / \mathrm{ml})$ & 9 & 10 & 8 \\
\hline $\operatorname{cortisol}(\mu \mathrm{g} / \mathrm{dl})$ & 5.33 & 4.7 & 3.73 \\
\hline $\mathrm{u}$-free cortisol ( $\mu \mathrm{g} /$ day $)$ & & 10 & \\
\hline \multicolumn{4}{|l|}{ Pituitary hormones } \\
\hline $\mathrm{GH}(\mathrm{ng} / \mathrm{ml})$ & & 0.67 & \\
\hline $\mathrm{LH}(\mathrm{mIU} / \mathrm{ml})$ & & $<0.1$ & \\
\hline $\mathrm{FSH}(\mathrm{mIU} / \mathrm{ml})$ & & 1.9 & \\
\hline PRL (ng/ml) & & 10.0 & \\
\hline \multicolumn{4}{|c|}{ Other hormones and related proteins } \\
\hline $\mathrm{TSH}(\mu \mathrm{IU} / \mathrm{ml})$ & & 0.029 & \\
\hline FT3 (pg/ml) & & 3.03 & \\
\hline FT4 (ng/dl) & & 0.92 & \\
\hline Vasopressin $(\mathrm{pg} / \mathrm{ml})$ & & 0.9 & \\
\hline PRA (ng/ml/hr) & & 7.5 & \\
\hline Aldosterone $(\mathrm{pg} / \mathrm{ml})$ & & 118 & \\
\hline Testosterone (ng/dl) & & 15 & \\
\hline Anti-pituitary antibody & & negative & \\
\hline
\end{tabular}

Table 1B. CRH, TRH, GRH, GnRH provocation test

\begin{tabular}{lllll}
\hline \multicolumn{1}{c}{ Time $(\mathrm{min})$} & \multicolumn{1}{c}{0} & \multicolumn{1}{c}{30} & \multicolumn{1}{c}{60} & \multicolumn{1}{c}{90} \\
\hline ACTH $(\mathrm{pg} / \mathrm{ml})$ & 6 & 55 & 59 & 50 \\
Cortisol $(\mu \mathrm{g} / \mathrm{dl})$ & 1.12 & 2.63 & 4.42 & 6.32 \\
$\mathrm{TSH}(\mu \mathrm{IU} / \mathrm{ml})$ & 0.016 & 0.105 & 0.120 & 0.124 \\
$\mathrm{GH}(\mathrm{ng} / \mathrm{ml})$ & 0.45 & 3.59 & 5.01 & 2.77 \\
$\mathrm{LH}(\mathrm{mIU} / \mathrm{ml})$ & 0.1 & 0.3 & 0.5 & 0.5 \\
FSH $(\mathrm{mIU} / \mathrm{ml})$ & 1.6 & 2.3 & 3.1 & 4.2 \\
PRL $(\mathrm{ng} / \mathrm{ml})$ & 9.3 & 15.7 & 14.9 & 14.2 \\
\hline
\end{tabular}

Table 1C. $5 \%$ hypertonic saline infusion test

\begin{tabular}{lccccc}
\hline \multicolumn{1}{c}{ Time $(\mathrm{min})$} & 0 & 30 & 60 & 90 & 120 \\
\hline $\mathrm{Na}(\mathrm{mmol} / \mathrm{l})$ & 139 & 143 & 145 & 148 & 152 \\
$\mathrm{pAVP}(\mathrm{pg} / \mathrm{ml})$ & 1.1 & 0.7 & 1.0 & 1.1 & 0.6 \\
\hline
\end{tabular}

RCC by transsphenoidal surgery. A cystic mass with elastic hard capsule, containing serous cloudy liquid, was removed from the sella, without evidence of infection of the content or of a pituitary tumor. Pathological examination of the fragment of the capsule showed ciliated columnar epithelial cells, compatible with RCC. Histological information of the adjacent normal pituitary tissue was not obtained because of insufficient material.

\section{Discussion}

RCC is a cystic lesion of the pituitary gland that is 

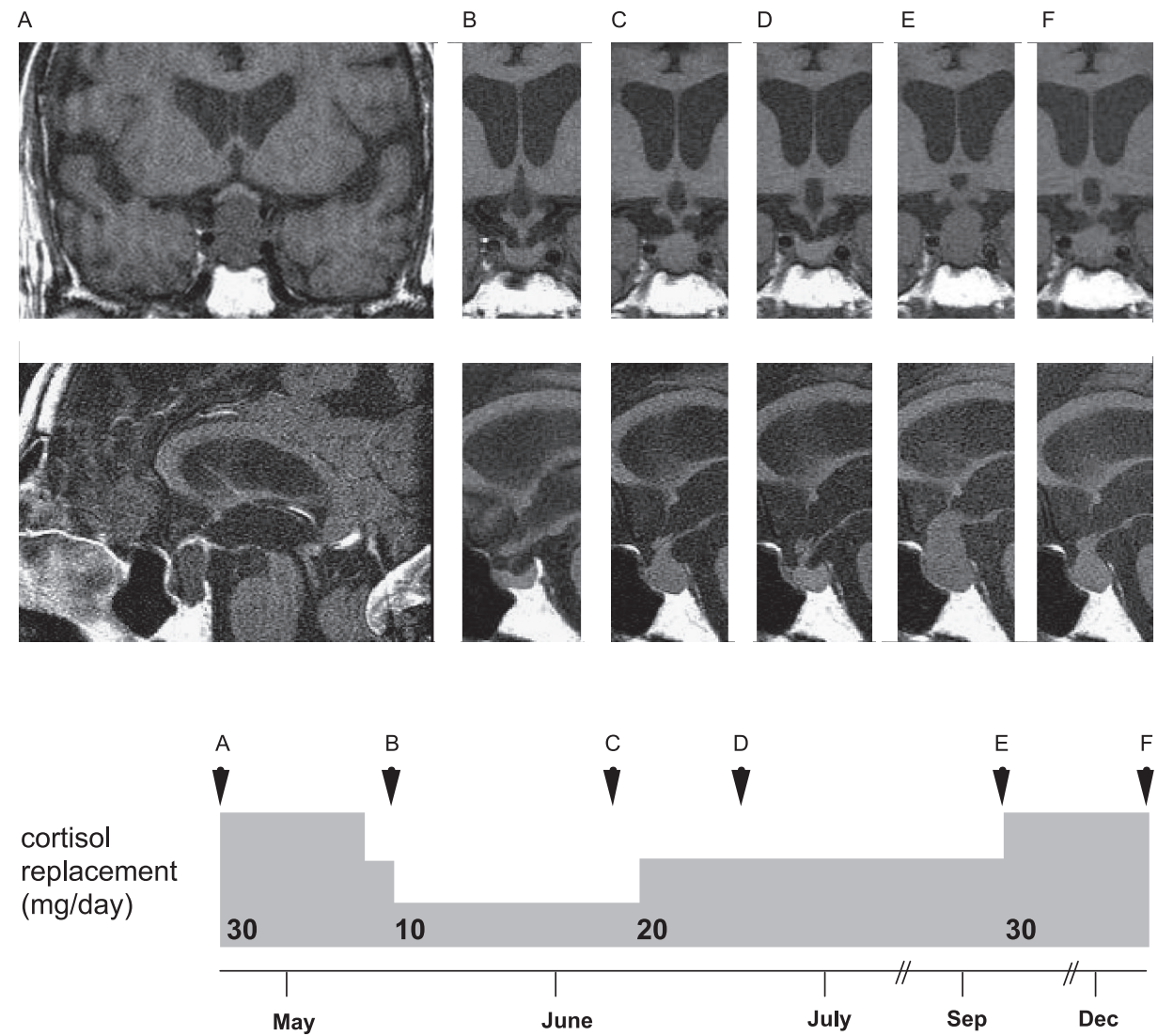

Fig. 1. Chronological changes of RCC in MRI examination (T1-weighted images without enhancement). A large cystic mass lesion with suprasellar extension was detected in the hypothalamo-pituitary region (A). After the start of cortisol replacement ( $30 \mathrm{mg}$ /day), a transient shrinkage of the mass was observed (B). However, it re-enlarged after the tapering of daily cortisol dose to $10 \mathrm{mg}$ /day $(\mathrm{C})$. Then it repeatedly shrank following the incremental increase of daily cortisol replacement $(\mathrm{C}$ to $\mathrm{D}$, and E to F).

thought to be an embryologic remnant of Rathke's pouch. The frequency of this disorder is reported to be relatively common at autopsy [1]. Furthermore, recent advances in imaging techniques like high resolution MRI increase the chance of detection of RCCs as one of the forms of "pituitary incidentaloma" [2]. Indeed, most of the RCCs are thought to remain asymptomatic throughout the lifetime. However, some cases of RCCs become symptomatic, causing a variety of clinical manifestations such as headache, hypopituitarism, and visual disturbances when they extend to the suprasellar region and compress the optic chiasm [3].

Usually the size of RCCs is known to be constant or only slowly growing. However, in the current case, relatively acute size change during a short period was observed. Increase and decrease in size are reported to occur following an intra-cystic bleeding and a cystic rapture, respectively [4], but we did not detect any signs of such events in MRI examination. Interestingly, a transient regression in size occurred following the start of cortisol replacement for his secondary hypoadrenocorticism, and since then relatively high doses of glucocorticoid administration were needed to prevent the re-enlargement of cystic size. Out of concern that long-term administration of high dose glucocorticoid might cause metabolic derangements such as central obesity, glucose intolerance, and hypertension, our patient was eventually treated by transsphenoidal surgery.

The mechanism whereby glucocorticoid influences the size of RCC is not clear. One possible explanation is that glucocorticoid simply affects the secretion rate of the intracystic fluid, because of the electrolyte-regulatory nature of the hormone in epithelial cells. Another more plausible explanation is the anti-inflammatory effect of glucocorticoid. Recent histological examina- 
tion has revealed that epithelial cells of RCCs produce mucinous substances, which can cause inflammation in or around the cysts [4-7]. It is also reported that the inflammation may even affect the normal pituitary cells and causes hypopituitarism [5, 8-10]. Inflammation is known to accompany cellular hyperfunction and/or dysfunction of the tissues involved due to the diverse effects of inflammatory cytokines. Thus, we assumed in this case that glucocorticoid may have elicited the shrinkage of the RCC by decreasing the amount of cystic fluid via its anti-inflammatory effect. Unfortunately, in this case, only small fragments of cystic capsule were obtained at surgery, and so the presence of inflammation could not be confirmed histologically.
Although substantial controversy regarding the therapeutic strategies of RCCs exists, emergent surgical treatment should be considered for cases with suprasellar extension with compression of the optic chiasm, to prevent permanent damage to visual function $[3,10$, 11]. However, our case may also suggest that glucocorticoids are effective in some cases of RCCs with suprasellar extension. If the acute growth of RCCs is confirmed not to be due to the intracystic bleeding by MRI examination, or if the physical condition of the patient is not suitable for emergency surgery, glucocorticoid administration may be one of the options for the medical treatment of RCCs.

\section{References}

1. Teramoto A, Hirakawa K, Sanno N, Osamura Y (1994) Incidental pituitary lesions in 1,000 unselected autopsy specimens. Radiology 193: 161-164.

2. Sanno N, Oyama K, Tahara S, Teramoto A, Kato Y (2003) A survey of pituitary incidentaloma in Japan. Eur J Endocrinol 149: 123-127.

3. Kanter AS, Sansur CA, Jane JA Jr, Laws ER Jr (2006) Rathke's cleft cysts. Front Horm Res 34: 127-157.

4. Naylor MF, Scheithauer BW, Forbes GS, Tomlinson FH, Young WF (1995) Rathke cleft cyst: CT, MR, and pathology of 23 cases. J Comput Assist Tomogr 19: 853-859.

5. Hama S, Arita K, Nishisaka T, Fukuhara T, Tominaga A, Sugiyama K, Yoshioka H, Eguchi K, Sumida M, Heike Y, Kurisu K (2002) Changes in the epithelium of Rathke cleft cyst associated with inflammation. $J \mathrm{Neu}$ rosurg 96: 209-216.

6. Ikeda H, Yoshimoto T (2002) Clinicopathological study of Rathke's cleft cysts. Clin Neuropathol 21: 8291.
7. Kim JE, Kim JH, Kim OL, Paek SH, Kim DG, Chi JG, Jung HW (2004) Surgical treatment of symptomatic Rathke cleft cysts: clinical features and results with special attention to recurrence. $J$ Neurosurg 100: $33-$ 40.

8. Saeki N, Sunami K, Sugaya Y, Yamaura A (1999) MRI findings and clinical manifestations in Rathke's cleft cyst. Acta Neurochir (Wien) 141: 1055-1061.

9. Nishioka H, Haraoka J, Izawa H, Ikeda Y (2006) Magnetic resonance imaging, clinical manifestations, and management of Rathke's cleft cyst. Clin Endocrinol (Oxf) 64: 184-188.

10. Sade B, Albrecht S, Assimakopoulos P, Vézina JL, Mohr G (2005) Management of Rathke's cleft cysts. Surg Neurol 63: 459-466.

11. Billeci D, Marton E, Tripodi M, Orvieto E, Longatti P (2004) Symptomatic Rathke's cleft cysts: a radiological, surgical and pathological review. Pituitary 7: 131137. 